\title{
Erratum to: New Concepts on Abdominoplasty and Further Applications
}

\author{
Juarez M. Avelar
}

Erratum to:

J.M. Avelar (ed.), New Concepts on Abdominoplasty and Further Applications, DOI 10.1007/978-3-319-27851-3

In the original version for the below papers, the name of the author was incorrect. It should read as Alex Boso Fioravanti.

Front Matter: On Table of Contents, Contributors list, pp. xvi, xx

Chapter 10: Importance of Concepts in Abdominoplasty and Liposuction in Breast Reduction, pp. 147

Chapter 12: Lipoabdominoplasty Combining a Wide Undermining of the Upper Abdomen with Complete Body Liposuction, pp. 179

The updated original online version for this chapter can be found at DOI:10.1007/978-3-319-27851-3

DOI:10.1007/978-3-319-27851-3_10

DOI:10.1007/978-3-319-27851-3_12

J.M. Avelar, MD

Head of the Brazilian Scientific Institute of Plastic and Reconstructive Surgery, Al Gabriel Monteiro da Silva, 620 Jd Europa, São Paulo, SP 01442-000, Brazil e-mail: juarezavelar@bol.com.br 